\title{
Editorial: Moving From a Curative to Preventative Pest Management Paradigm
}

\author{
Helda Morales $^{1 *}$, Inge Armbrecht ${ }^{2}$, David Gonthier ${ }^{3}$ and Kris A. G. Wyckhuys ${ }^{4,5,6,7}$ \\ ${ }^{1}$ Departamento de Agricultura, Sociedad y Ambiente, El Colegio de la Frontera Sur, San Cristóbal de Las Casas, Mexico, \\ ${ }^{2}$ Departamento de Biología, Univesidad del Valle, Cali, Colombia, ${ }^{3}$ Department of Entomology, University of Kentucky, \\ Lexington, KY, United States, ${ }^{4}$ Chrysalis Consulting, Hanoi, Vietnam, ${ }^{5}$ China Academy of Agricultural Sciences, Beijing, \\ China, ${ }^{6}$ University of Queensland, Brisbane, Australia, ${ }^{7}$ Fujian Agriculture and Forestry University, Fuzhou, China
}

Keywords: agroecology, pest prevention, sustainable agriculture, biological pest control, traditional knowledge

\author{
Editorial on the Research Topic
}

\section{Moving From a Curative to Preventative Pest Management Paradigm}

Over the past decades, crop protection research, education and outreach have increasingly focused on pest management as a reactive approach. Though the financial and human resources invested for that purpose are enormous, pests continue to be an increasing problem of global proportionsand are of particular concern in large-scale, simplified and chemically-intensified agroecosystems. This curative pest control strategy (and particularly farmer's over-reliance on synthetic pesticides) negatively impacts biodiversity, farmer and consumer health and farm profitability while directly contributing to global environmental change. Yet, first-hand experience of small farmers across the globe has shown that a preventative approach (e.g., crop and genetic diversification, tailored soil, water and fertility management, varietal resistance and conservation biological control) effectively

OPEN ACCESS

Edited and reviewed by:

Stacy Michelle Philpott, University of California, Santa Cruz, United States

*Correspondence: Helda Morales

hmorales@ecosur.mx

Specialty section:

This article was submitted to Agroecology and Ecosystem Services,

a section of the journal

Frontiers in Sustainable Food Systems

Received: 03 November 2021 Accepted: 14 November 2021 Published: 03 December 2021

Citation: Morales H, Armbrecht I, Gonthier D and Wyckhuys KAG (2021) Editorial: Moving From a Curative to Preventative Pest Management Paradigm

Front. Sustain. Food Syst. 5:808124. doi: 10.3389/fsufs.2021.808124 defuses crop herbivores and proves to be far more efficient, cost-effective and environmentallysound than conventional pest management strategies. A paradigm shift is urgently needed to help stall or revert the biodiversity crisis and to become a core component of initiatives that pursue agroecological transitions.

In this Research Topic we intend to collate the state of the art of research on pest prevention upon experiences from various agroecosystems around the globe.

Although agroecology promotes principles, not recipes, it is important to have empirical examples that serve as inspiration for other contexts. This special issue highlights how designing agroecosystems for preventative pest management can take many forms and functions and can be implemented across large and small scales. Specifically, several studies demonstrate that intentional selection of vegetative features can alter the natural behavior of pests, limit host finding, and dilute host-crop resources, ultimately limiting their ability to reach damaging levels. For example, intercropping blueberry orchards with peppermint, which release high levels of volatile organic compounds, deter spotted-winged Drosophila flies from ovipositing in berries (Gowton et al.). While diversifying field edges with woody habitat reduced yield loss by the sunflower moth 4-fold compared to bare, undiversified field edges (Kross et al.). Other studies highlight how diversified agroecosystems harbor more structural and trophic resources that allow natural enemies to better persist over time to limit pests preventatively (Iuliano and Gratton). For example, in shaded coffee farms of southern Mexico, where agroforestry practices provide ample resources for high densities of bird and bat species, removal of these predators results in increased abundance of herbivores on coffee (Schmitt et al.). Even in greenhouses, the most simplified agroecosystems, introducing prey resources to preventatively establish predators and parasitoids before the arrival of pests can improve the success of biological control programs beyond curative release strategies (Pijnakker et al.). 
Agriculture is a dynamic, inter-connected socio-ecological system. While work along ecological or agronomic fronts is important to advance preventative pest management, its social facets cannot be disregarded. As a central premise of agroecology, farmer-scientist crosstalk and collaboration is crucial to empower country folk and to mobilize the wealth of traditional, indigenous knowledge. Meanwhile, by engaging anthropologists, one can pinpoint key knowledge gaps and identify needs for further awareness-raising — as elegantly shown for Peruvian mestizo farmers (Beltran-Tolosa et al.). Even within seemingly monotonous agri-food systems e.g., California urban community gardens, farmer knowledge is surprisingly diversemolded by ethnicity, experience and gender (Liere et al.). In such settings, mental models can help to detect how particular beliefs obstruct farmers' ultimate adoption of biodiversitybased practices such as biological control (Bardenhagen et al.). Involvement of social scientists is also sorely needed to gauge the economic weight of preventative pest control-an exercise which is done in a mere $4 \%$ of instances in the Asia-Pacific (Wyckhuys et al.). Yet, these few economic assessments do show how monetary impacts are substantial; vegetable growers that harness biodiversity for pest control reap $78 \%$ higher profits and cut their (pesticide) expenditures by hundreds of dollars. Echoing recommendations by the 57 authors that underwrote our Special Topic, an interdisciplinary "Humboldtian" perspective is thus indispensable to bring about transitions toward sustainable food systems.

As presented in the overview, most research and funding is placed on conventional approaches to pest control, especially directed to agribusiness and formulas which could be easily applied at large scales. Given that widespread unintended consequences have already been documented, we need a drastically different philosophy. The articles published in this special issue witness the transition from this reactive approach to a preventive approach in terms of pest management. It is increasingly becoming more evident that the new agriculture for a sustainable future needs much more qualified science, given that its main input is knowledge. A new paradigm for agriculture is not an easy task. It implies the recognizing and sharing of traditional peasant/indigenous wisdom and scientific approach. Scientists should no longer ignore that there are efficient millenary ancestral practices in preventing pest outbreaks, which need to be put under scrutiny. Agronomists and agroecology practitioners need an ecological lens to develop autonomous ecosystem services to avoid pest losses. Multiscale and transdisciplinary working probably will be one of the keys to reach sustainable agriculture, but this will require profound changes in our institutions of higher education. We hope that this Special Topic will contribute to start those changes.

\section{AUTHOR CONTRIBUTIONS}

HM proposed the idea of the Research Topic and invited the other editors and for the editorial wrote the introduction. DG wrote the ecological synthesis. KW the social sciences contributions. IA the conclusions. We all edited the manuscripts.

Conflict of Interest: The authors declare that the research was conducted in the absence of any commercial or financial relationships that could be construed as a potential conflict of interest.

Publisher's Note: All claims expressed in this article are solely those of the authors and do not necessarily represent those of their affiliated organizations, or those of the publisher, the editors and the reviewers. Any product that may be evaluated in this article, or claim that may be made by its manufacturer, is not guaranteed or endorsed by the publisher.

Copyright (c) 2021 Morales, Armbrecht, Gonthier and Wyckhuys. This is an openaccess article distributed under the terms of the Creative Commons Attribution License (CC BY). The use, distribution or reproduction in other forums is permitted, provided the original author(s) and the copyright owner(s) are credited and that the original publication in this journal is cited, in accordance with accepted academic practice. No use, distribution or reproduction is permitted which does not comply with these terms. 